\title{
Effect of a benzalkonium chloride surfactant-sodium hypochlorite combination on elimination of Enterococcus faecalis
}

\author{
Aleksandr Baron, DDS ${ }^{a}$, Kimberly Lindsey, DDS $^{\text {a }}$,Stephanie J Sidow, DDS ${ }^{\text {a }}$, Douglas \\ Dickinson, $\mathrm{PhD}^{\mathrm{a}}$, Augustine Chuang, $\mathrm{PhD}^{\mathrm{b}}$, James $\mathrm{C}$ McPherson, III, $\mathrm{PhD}^{\mathrm{b}}$ \\ From the a U.S. Army Dental Activity, Fort Gordon, GA; and ${ }^{\mathrm{b}}$ D.D.Eisenhower Army Medical \\ Center, Department of Clinical Investigation, Fort Gordon, GA.
}

Key Words: Benzalkonium chloride, Biofilm,Dentin Tubules, Enteroccocusfaecalis

Corresponding Author: Dr. Kimberly Lindsey, U.S. Army Dental Activity, Department of Endodontics, Fort Gordon, GA 30905. E-mail address: kimberly.w.lindsey.mil@mail.mil

Acknowledgements:The opinions or assertions contained herein are the private views of the authors and not to be construed as official or as reflecting the views of the U.S. Army Medical Department, Department of the Army, or the Department of Defense. Citation of commercial organizations and trade names in the manuscript do not constitute any official Department of the Army or Department of Defense endorsement or approval of these organizations. The authors deny any conflicts of interest related to this study. The authors wish to thank Richard Topolski, PhD, Georgia Regents University for statistical analysis. 
2 Abstract

3 Introduction: The purpose of this investigation was to determine the effect of a sodium

4 hypochlorite-surfactant combination on the removal of Enterococcus faecalisfrom infected teeth.

5 Methods: Sixty-four extracted human single canal anterior teeth were prepared with rotary

6 instrumentation and sterilized. Teeth were divided into four groups; $N=16$. Three experimental

7 groups were inoculated with $E$. faecalis and cultured for 21 daysbefore use:Positive Control

8 Group: no irrigation; $\mathrm{NaOCl}$ Group: irrigated with $5 \mathrm{~mL}$ of $6 \% \mathrm{NaOCl}$; and $\mathrm{NaOCl} / \mathrm{BAK}$ Group:

9 irrigated with $5 \mathrm{~mL}$ of $6 \% \mathrm{NaOCl} / \underline{0.008 \%}$ benzalkonium chloride (BAK). The Negative Control

10 Group received media only, no inoculate.Paper point sampling of the canalswas obtained pre-

11 irrigation (S1) for all fourgroups, andfor two groupspost-irrigation (S2)

12 todetermineremainingcolony forming units (CFUs). After sampling, all teethwere split in halfand

13 evaluated for bacterial viabilityCFUsand penetration of dentinal tubules using fluorescent vital

14 dye staining and confocal laser scanning microscopy (CLSM).

15 Results: Comparison of pre- and post-irrigation paper point samples from the two irrigated 16 groupsshowed a significant reduction in bacterial canal load ( $p<0.001$, Kruskal-Wallis), with a 17 significantly lower load in the NaOCl/BAKGroup than in the NaOCl Group $(p=0.001$, Mann18 Whitney $\mathrm{U}) ; 68.8 \%$ of the $\mathrm{NaOCl} / \mathrm{BAK}$ samples gave no recoverable counts. In contrast, no 19 significant difference between these groups was found for counts recovered from dentin. CLSM 20 showed no differences in tubule penetration.

21 Conclusions:The addition of $\mathrm{BAK}$ to $\mathrm{NaOCl}$ significantly reduced the number of remaining 22 bacteria within the canal after irrigation compared to $\mathrm{NaOCl}$ alone. 


\section{INTRODUCTION}

26 Endodontic success relies largely on chemo-mechanical removalof bacteria, bacterial

27 endotoxin, and debris from the root canal system $(1,2)$. The chemical portion is often facilitated

28 bycommon endodontic irrigantssuch as sodium hypochlorite $(\mathrm{NaOCl})$ or $2 \%$ Chlorhexidine

29 (CHX). $\mathrm{NaOCl}$ has reported advantages over $\mathrm{CHX}$ such astissue dissolution and disruption of a 30 biofilm (3). However, research hasdemonstrated thatduring instrumentation and irrigation with $315 \% \mathrm{NaOCl}$, nearly $1 / 3$ to $1 / 2$ ofthe root canalremains contaminated (4). Enterococcus faecalis is 32 a commonly isolated species that may play a role in persistent endodontic infections (5). It has 33 the ability to form a biofilm in monoculture (6), can adapt to harsh environmental changes 34 andinvade the dentinal tubules, thereby resisting endodontic medicaments and becoming, 35 difficult to eliminate (5).

Bacterial biofilms are the most common cause of persistent infection (7) and apical periodontitis 37 is referred to as 'an intraradicular biofilm-induced chronic disease' (8). Microorganisms in 38 biofilms are far better protected, and can be greater than one thousand times more resistant to 39 antimicrobial agentsas the same organisms in planktonic form $(8,9)$, and from 2-1000-fold more 40 resistant to antimicrobial agents than corresponding planktonic organisms $(9,10)$. Bacterial 41 biofilmsshow extremehydrophobic properties, greatly surpassing Teflon for repellingwater and 42 lower surface tension liquids (11). High surface tension (12) could affect the ability of $\mathrm{NaOCI}$ to 43 penetrate into dentine and thus reduce its antibacterial effectiveness within dentinaltubules.

44 Externally added surfactants often affect the stability of biofilm structures negatively (13), 45 disrupting hydrophobic interactions in biofilm cohesion (14).BAK is asurfactantcommonly used 46 to improvewetting propertiesand was found to exhibit an overall 70-fold reduction in biofilm 47 accumulation (15). BAK combined with $\mathrm{NaOCl}$ could reduce the bacterial load to a greater extent 48 than $\mathrm{NaOCl}$ alone, and allow further dentinal tubular diffusion of $\mathrm{NaOCl}$.Bukiet et al (16) 
demonstrated that combining BAKand $\mathrm{NaOClreduced} \mathrm{the} \mathrm{contact} \mathrm{angle} \mathrm{of} \mathrm{NaOCl}$ by over $50 \%$,butleft the antibacterial efficiency unchanged. However, this study did not evaluate the

51 effect on diffusion of the modified $\mathrm{NaOCl}$ into dentinal tubules or its antibacterial effect on a 52 biofilm ex vivo.The aims of this studywere: 1) tomeasure the effect of $\mathrm{BAK}$ and $\mathrm{NaOCl}$ on

53 removal of a biofilmof $E$. faecalisin a human tooth modeland 2) to compare the diffusion of the 54 irrigant into the dentinal tubules with and without the surfactant using confocal laser scanning 55 microscopy (CLSM).

\section{MATERIALS AND METHODS}

\section{Specimen Preparation}

58 This study was approved by the Dwight D. Eisenhower Army Medical Center Research

59 Regulatory Compliance Office, and teeth collected in accordance with the USA Fort Gordon 60 Dental Activity "Collection of Extracted Teeth" standard operating procedure. Extracted human 61 anterior maxillary and mandibular teeth were stored at $4^{\circ} \mathrm{C}$ in $0.9 \%$ sodium chloride containing $621 \%$ sodium azide to retard bacterial growth. Seventy-six teeth were radiographed in a mesio63 distal direction to screen for the presence of a single canal, resulting in a total sample size of $64 \mathrm{~N}=64$. The tooth length was standardized to $17 \mathrm{~mm}$ by decoronating with an Isomet 5000 saw 65 (Buehler, Lake Bluff, IL). The working length was determined as the point in which a \#10 file 66 was justvisible with 20X magnification in the apical foramen. Each canal was instrumented to a 67 size 50/.04 using Profile Vortex rotary nickel-titanium instruments (Dentsply, York, PA). The 68 canal was flooded with $6 \% \mathrm{NaOCl}$ (Vista Dental Products, Racine, WI) and replenished after 69 each file using a 30 gauge side-vented needle (Max-I-Probe, Dentsply, Elgin, IL).The smear 70 layer was removed with $17 \%$ EDTA irrigation for one minute, followed by a final rinse of $5 \mathrm{~mL}$ of $716 \% \mathrm{NaOCl}$. Five milliliters of $5 \%$ sodium thiosulfatewere used to inactivate the $\mathrm{NaOCl}$ followed 72 by $5 \mathrm{~mL}$ of sterile saline. The apical foramen was sealed using cyanoacrylate and the root 73 surface was sealed with varnish. Teeth wereplaced individuallyin $1.5 \mathrm{~mL}$ microtubes (Sarstedt, 
74 Numbrecht, Germany), and steam autoclaved at $121^{\circ} \mathrm{C}$ for 30 minutes, after which the samples

75 were handled under strict aseptic measures. The samples were randomly assigned to four

76 groups of $\mathrm{N}=16$. Positive Control Group: no irrigation (positive control); $\mathrm{NaOCl}$ Group: irrigated

77 with $5 \mathrm{~mL}$ of $6 \% \mathrm{NaOCl}$; and $\mathrm{NaOCl} / \mathrm{BAK}$ Group: irrigated with $5 \mathrm{~mL}$ of $6 \% \mathrm{NaOCl} / 0.008 \%$

78 benzalkonium chloride (BAK) prepared per Bukiet et al (16). The Negative Control Group

79 received media only, no inoculate.

\section{Infection with $E$. faecalis}

The Negative Control samples were filled with sterile brain-heart infusion $(\mathrm{BHI})$ broth (Becton Dickinson and Company, Sparks, MD). The other threegroupswere infected using a 24-hour pure culture suspension of E. faecalis (ATCC 19434) cultivated inBHI and then inoculatedwith $15 \mu \mathrm{L}$ of $\mathrm{a} 1 \times 10^{8} \mathrm{CFU} / \mathrm{mLs}$ spension of $E$. faecalis(determined by serial dilution and plating). Teeth were incubated at $37^{\circ} \mathrm{C}$ and $95 \%$ humidity for 21 days, during which the BHIwas removed from the canalby gentle aspiration and replenishedevery 72 hours.

\section{Determination of Bacterial Viability}

After 21 days, the media was removed from all of the specimens. A sterile paper point was used at working length to sample the canals from all fourgroups (S1). After paper point sampling, the $\underline{\mathrm{NaOCland}} \mathrm{NaOCl} / \mathrm{BAKG}$ roups were irrigated with $5 \mathrm{~mL}$ of the respective experimental irrigant as described above. All irrigants were delivered at a flow rate of $0.04 \mathrm{~mL} / \mathrm{s}$ using a side-vented $30 \mathrm{G}$ needle (Max-I-Probe, Dentsply, Elgin, IL). A second post-irrigation paper point sample (S2) was obtained from each canal in the $\mathrm{NaOCl}$ and $\mathrm{NaOCl} / \mathrm{BAKG}$ roupsas described above. The positive andnegative controls received no irrigation and were only sampled pre-irrigation.

The paper points were placed individually in $1.5 \mathrm{~mL}$ microtubes containing $0.5 \mathrm{~mL}$ of $\mathrm{BHI}$ broth and vortexed at the highest speed for three consecutive intervals of 15 seconds each. One hundred microliters of media was plated on $\mathrm{BHI}$ agar in triplicate and the remainder stored at 
$4^{\circ} \mathrm{C}$. All plates were incubated at $37^{\circ} \mathrm{C}$ and $95 \%$ humidity for 24 hours after which the colonies were enumerated using a colony counter (Protocol, Synbiosis, Frederick, MD). If any sample was too numerous to count, it was diluted, plated and counted.

\section{Pulverization and CLSM Analysis}

102 Teeth were prepared for the bacterial count determination and bacterial viability staining within 103 the dentin tubules using CLSM as follows(17): A shallow groove was made longitudinally in the 104 tooth using a diamond coated discand split using a single-edged surgical blade and a surgical 105 mallet. One-half of the tooth was placed in a microtube and stored at $-80^{\circ} \mathrm{C}$. Subsequently, this 106 tooth half was placed in liquid nitrogen, ground to a fine powder, and weighed. One milliliter of 107 media was added, and 100 $\mu$ Lplated for CFU determination in triplicate. The surface of 108 theremaining sample half was stained with the fluorescent LIVE/DEAD® BacLight ${ }^{\mathrm{TM}}$ Bacterial 109 Viability stain (Molecular Probes, Eugene, OR) according to the methods outlined in Ma et al 110 (18) and analyzed with CLSM (Carl Zeiss Microimaging, Thornwood, NY).

\section{STATISTICS}

112 Descriptive statistics evaluation of bacterial countsand non-parametric tests (as the data were 113 not normally distributed)were performed using Prism 6.0 software (alpha=0.05). Normality of 114 distributions were assessed using the D'Agostino and Pearson omnibus and the Shapiro-Wilk 115 normality tests. Group values are shown as median and interquartile range.

\section{RESULTS}

117 All teeth in the Negative Control Group showed no bacterial growth from S1paperpoint samples 118 (Fig. 1A). S1 values forthe three inoculatedgroups hadmedians (interquartile ranges) of $1192.46(2.27-2.59) \times 10^{5}, 2.36(2.24-2.61) 0.06 \times 10^{5}$, and $2.31(1.90-2.62) \times 10^{5} \mathrm{CFUs} /$ point 120 respectively, with no significant difference between these values ( $p=\underline{0.6}$, Kruskal-Wallis 
121 test).Both experimental irrigated groups ( $\mathrm{NaOCl}$ and $\mathrm{NaOCl} / \mathrm{BAK})$ indicated efficacy with

122 regards to bacterial load reduction seenin S2 sampling (Fig. 1A, $p<0.001$, Kruskal-Wallis test).

123 In the $\mathrm{NaOClGroup,} \mathrm{all} \mathrm{samples} \mathrm{gave} \mathrm{viable} \mathrm{counts,} \mathrm{with} \mathrm{a} \mathrm{median} \mathrm{of} 6.50 \times 10^{4}(4.13-8.63 \times$

$12410^{4}$ ) CFUs/point, but in the $\mathrm{NaOCl} / \mathrm{BAKGroup}$, viable bacteria were only recovered in $5 / 16$

125 samples, resulting in a median of $0\left(0-1 \times 10^{4}\right) \mathrm{CFUs} /$ point. That is, $68.8 \%$ of the

$126 \mathrm{NaOCl}$ /BAKGroupsamples showed complete elimination of bacteria from the canal. The

127 reduction in canal bacterial load determined by paperpoint sampling showed a significant

128 difference between the two treatments, with the $\mathrm{NaOCl} / \mathrm{BAK}$ combination being more effective

129 than $\mathrm{NaOCl}$ alone $(\mathrm{p}=0.001$, Mann-Whitney $\mathrm{U}$ test). The average load reduction in the

$130 \mathrm{NaOClGroup} \mathrm{was} 71.8 \%$, compared to $87.8 \%$ in the $\mathrm{NaOCl} / \mathrm{BAKG}$ roup.Considering only the five 131 positive samples in the $\mathrm{NaOCl} / \mathrm{BAKGroup}$, there was a60.8\% reduction.

132 Consistent with the results from paperpoint testing, the Negative Control Group showed no 133 viable counts in the pulverized tooth, while in the Positive Control Group all samples showed a 134 substantial bacterial load with a median (interquartile range) of $8.90(6.76-12.37) \times 10^{2}$ $135 \mathrm{CFU} / \mathrm{mg}$ (Fig. 1B). Significantly lower values of viable bacteria were found in the irrigated groups $136(\mathrm{p}<0.001, \mathrm{Kruskal-Wallis} \mathrm{test).} \mathrm{In} \mathrm{the} \mathrm{NaOCIGroup,} \mathrm{all} \mathrm{samples} \mathrm{gave} \mathrm{viable} \mathrm{counts,} \mathrm{with} \mathrm{a}$ 137 median (interquartilerange) of 85 (72-108) CFU/mg, representing a $91.0 \%$ reduction from the 138 positive control.In the $\mathrm{NaOCl} / \mathrm{BAKG}$ roup one sample gave no viable counts, with a median 139 value of $85 \mathrm{CFU} / \mathrm{mg}(75-111)$, a $92 \%$ reduction fromthe positive control. There was no significant 140 difference between the $\mathrm{NaOCl}$ and $\mathrm{NaOCl} / \mathrm{BAK}$ Groups dentin in CFU/mg ( $\mathrm{p}=\underline{0.8}$, Mann141 Whitney U test).

142 When the distribution of dead bacteria in dentin tubules was examined by fluorescent dye 143 staining, a modest increase in clearance of bacteria over a few tens of micrometers was seen 144 near the canal wall surface, evidenced by the lack of any staining, but there was no large 
increase in the depth of killing of bacteria within the tubules, with propidium iodide staining limited to about 50-150 $\mu \mathrm{m}$ from the surface (Fig 2).

\section{DISCUSSION}

149 Research has elucidated the complex interactions, mainly hydrophobic, which allow for 150 resiliency within an established biofilm of E. faecalis (19). Several studies $(12,16,20)$ have 151 reported a significant reduction in surface tension of $\mathrm{NaOCl}$ when combined with surfactants, 152 andthis reduced surface tension may allow for greater dissolution of these hydrophobic 153 interactions. Previous research demonstrated that addition of a surfactant to $\mathrm{NaOCl}$ has little to 154 no effect on its ability to enhance tissue dissolution $(21,22)$. Theidentitiesofsurfactants addedto $155 \mathrm{NaOCl}$ to enhance the eradication ofa monoculture biofilm found within the dentinal tubules are 156 proprietaryand undisclosed. This is the first studyto evaluate the ability of BAK, combined with $157 \mathrm{NaOCl}$, to disrupt an ex-vivo biofilm of $E$. faecalis. We found the addition of $\mathrm{BAK}$ to $\mathrm{NaOCl}$ 158 resulted in a significant difference in the elimination of $E$. faecalis within the canals as 159 determined by paper point sampling of the canal.The NaOCl/BAK Group showed a substantial 160 difference from $\mathrm{NaOCl}$ Group in the pattern of clearance of bacteria from the canal. However, 161 the addition of $\mathrm{BAK}$ to $\mathrm{NaOCl}$ resulted in no significant difference in bacterial reduction within 162 the dentinal tubules of the experimental teeth, as measured by the CFU/mg of powdered dentin 163 (Fig. 1B). Consistent with these findings, examination of bacterial distribution by fluorescent 164 staining and CLSM demonstrated equal penetration into the dentinal tubules in both 165 experimental groups, (Fig. 2) withpenetration of $\mathrm{NaOCl}$ or $\mathrm{NaOCl}$ plus surfactant not exceeding 166 more than $150 \mu \mathrm{m}$. That is, representativeCLSM images (Fig 2) show noadded benefit of adding 167 the surfactant BAK to enhance dentinal tubular penetration. This could solely be attributed to 168 time;Zou et al (23) showed that 20 minutes of $6 \% \mathrm{NaOCl}$ was necessary for maximum 
penetration of up to $300 \mu \mathrm{m}$ in dentinal tubules. Our irrigation was completed in 5 minutes with only $5 \mathrm{~mL}$ of irrigant consistent with studies showing inhibition of $E$. faecalis with $\mathrm{NaOCl}$ exposure ranging from 30 seconds to 2 minutes (24-26). Consequently, both irrigant groups 172 killed a significant amount of bacteria within the tubules near the canal wall surface, which may 173 have created an organic barrier that prevented further irrigant progression. Thissupports the 174 findings of Wang et al(27) who determined that older biofilms within dentinal tubules were more 175 resistant to chemical disinfection.

One limitation of thisstudy was the use of a monoculture biofilm, which provided a straightforward experimental design. $\underline{\text { However}}$, it is evident that oral microbes are able to invade root canals and form a complex biofilm comprised of several species $(9,10)$. We chose to focus on E. faecalis as it is a species commonly found in persistent infections (5),consistent with its ability to form a biofilm even in monoculture $(6,19)$. Examination of the positive control vital dye stained canal surfaces and tubules (Fig 2C) revealed dense masses of bacteria consistent with

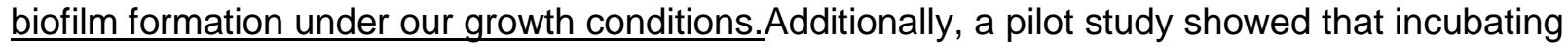
the teeth for 3 weeks with $E$. faecalisprovided adequate CFUs for the investigation(data not shown). The effect of surfactant on a complex biofilm remains to be investigated. An additional potential limitation is that although $E$. faecalis has been well-documented in infected root canal systems, it is found primarily in teeth with previous endodontic treatment (28-30), which was not incorporated in this study. However, the extensive literature employing this organism in clearance studies supports its use in initial monoculture studies without prior endodontic treatment, as here, where adhesion to mineral surfacesand invasion of tubules would be expected to be somewhat similar between treated and untreated teeth.

The use of paper point sampling may be a limitation. The paper point sampling method has been found to be less sensitive for monitoring treatment strategies within the canal (31). The 
paper point method was used to confirm the bacterial status of the canal before pulverization of the tooth, which has been shown to dramatically improve the sensitivity of culturing (32-34).

Our results are in agreement with other studies $(18,23,35)$, which report a reduction in bacterial load but not complete elimination when current irrigation techniques combined with surfactants are employed. Research evaluating what effect this may have on success of outcomes in endodontics is yet to be realized, as no study has shown the critical level of bioburden thattips the scale towards chronic inflammation in periapical periodontitis. It remains essential that research focuses on improving irrigation strategies and obturation of the root canal system.In conclusion, our results demonstrate that the addition of a surfactant, benzalkonium chloride to $\mathrm{NaOCl}$, can significantly improve microbial clearance of heavily infected straight canals. It is important to note that BAK is an FDA category 3 antiseptic, and the application of surfactants in patient treatment will require appropriate testing for safety.Supplementation of irrigation with adjunct agitation has been shown to enhance bacterial clearance (36).Future research could incorporate agitation to potentiallyaid in diffusion of a surfactant-modified irrigant while encouraging removal of cellular debris.

\section{REFERENCES}

210 1.Sjögren U, Figdor D, Persson S, et al. Influence of infection at the time of root filling on the 211 outcome of Eradication of endodontic infection endodontic treatment of teeth with apical 212 periodontitis. Int Endod J 1997;30:297-306.

213 2.Katebzadeh N, Sigurdsson A, Trope M. Radiographic evaluation of periapical healing after 214 obturation of infected root canals: an in vivo study. Int Endod J2000;33:60-66.

215 3. Clegg MS, Vertucci FJ, Walker C, et al. The effect of exposure to irrigant solutions on 
apical dentin biofilms in vitro. J Endod 2006;32:434-7.

217 4. Byström A, Sundqvist G. The antibacterial action of sodium hypochlorite and EDTA in 60 218 cases of endodontic therapy. Int Endod J1985;18:35-40.

219 5.Portenier I, Waltimo TM, Haapasalo M.Enterococcus faecalis-the root canal survivor and 220 'star'in post-treatment disease. Endod Topics 2003;6:135-59.

221 6.Chavez de Paz LE, Bergenholtz G, Svensäter G. The effects of antimicrobials on endodontic 222 biofilm bacteria. J Endod 2010;36:70-77.

223 7. Costerton JW, Stewart PS, Greenberg EP. Bacterial biofilms: A common cause of persistent 224 infections. Science 1999;284:1318-22.

225 8.Nair PNR, Henry S, Cano V, et al. Microbial status of apical root canal system of human 226 mandibular first molars with primary apical periodontitis after "one-visit" endodontic 227 treatment.Oral Surg Oral Med Oral Pathol Oral Radiol Endod 2005;99:231-52.

228 9. Nair PNR. On the causes of persistent apical periodontitis: a review. Int Endod J $229 \quad 2006 ; 39: 249-81$

230 10. Svensäter G, Bergenholtz G. Biofilms in endodontic infections. Endod Topics 2004;9:27-36.

231 11. Epstein AK, Pokroy B, Seminara A, et al. Bacterial biofilms show persistent resistance to 232 liquid wetting and gas penetration. Proc Natl Acad Sci U S A2011;108:995-1000.

233 12. Giardino L, Ambu E, Becce C, et al. Surface tension comparison of four common root canal 234 irrigants and two new irrigants containing antibiotic. J Endod 2006;32:1091-93.

235 13. Schreiberová O, Hedbávná P, Čejková A, et al. Effect of surfactants on the biofilm of 236 Rhodococcus erythropolis, a potent degrader of aromatic pollutants. N Biotechnol 2012;30:6223768 

2010;36:793-96.

14. Chen X, Stewart PS. Biofilm removal caused by chemical treatments. Water Res 2000;34:4229-33.

15. Jaramillo DE, Arriola A, Safavi K, et al. Decreased bacterial adherence and biofilm growth on surfaces coated with a solution of benzalkonium chloride. J Endod 2012;38:821-25.

16. Bukiet F, CoudercG, Camps J, et al. Wetting properties and critical micellar concentration of benzalkonium chloride mixed in sodium hypochlorite. JEndod 2012;38:1525-29.

17. Tran KT, Torabinejad M, Shabahang S, et al. Comparison of efficacy of pulverization and sterile paper point techniques for sampling root canals. J Endod 2013;39:1057-59.

18. Ma J, Wang Z, Shen $Y$, et al. A new noninvasive model to study the effectiveness of dentin disinfection by using confocal laser scanning microscopy. J Endod 2011;37:1380-85.

19.George S, Kishen A, Song P. The role of environmental changes on monospecies biofilm formation on root canal wall by Enterococcusfaecalis. J Endod2005;31:867-72.

20.Palazzi F, Morra M, Mohammadi Z, et al. Comparison of the surface tension of $5.25 \%$ sodium hypochlorite solution with three new sodium hypochlorite-based endodontic irrigants. Int Endod J 2012;45:129-135.

21. Stojicic S, Zivkovic S, Qian W, et al. Tissue dissolution by sodium hypochlorite: effect of concentration, temperature, agitation, and surfactant. J Endod 2010;36:1558-1562.

22. Clarkson RM. Kidd B, Evans GE, et al. The Effect of Surfactant on the Dissolution of Porcine Pulpal Tissue by Sodium Hypochlorite Solutions. J Endod2012;38:1257-60.

23. Zou L, Shen Y, Li W, et al. Penetration of sodium hypochlorite into dentin. J Endod 
24. Baumgartner JC, Johal S, Marshall JG. Comparison of the antimicrobial efficacy of $1.3 \%$ $\mathrm{NaOCl} / \mathrm{BioP}$ ure MTAD to $5.25 \% \mathrm{NaOCl} / 15 \%$ EDTA for root canal irrigation. J Endod 2007;33:48-51.

262 25. Vianna ME, Gomes BP. Efficacy of sodium hypochlorite combined with chlorhexidine 263 against Enterococcus faecalis in vitro. Oral Surg Oral Med Oral Pathol Oral Radiol Endod $264 \quad 2009 ; 107: 585-9$.

265 26. Gomes BP, Ferraz CC, Vianna ME, et al. In vitro antimicrobial activity of several 266 concentrations of sodium hypochlorite and chlorhexidine gluconate in the elimination of 267 Enterococcus faecalis. Int Endod J 2001;34:424-8.

268 27. Wang Z, Shen Y, Haapasalo M. Effectiveness of endodontic disinfecting solutions against 269 young and old Enterococcus faecalis biofilms in dentin canals. J Endod 2012;38:1376-79.

270 28. Sundqvist G, Figdor D, Persson S, et al. Microbiologic analysis of teeth with failed 271 endodontic treatment and the outcome of conservative re-treatment. Oral Surg Oral Med Oral 272 Pathol Oral Radiol Endod 1998;85:86-93.

273 29. Sunde PT, Olsen I, Debelian GJ, et al. Microbiota of periapical lesions refractory to 274 endodontic therapy. J Endod 2002;28:304-10.

275 30. Chavez de Paz LE. Redefining the persistent infection in root canals: possible role of biofilm 276 communities. J Endod 2007;33:652-62.

277 31.Sathorn C, Parashos $\mathrm{P}$, Messer HH. How useful is root canal culturing in predicting 278 treatment outcome? J Endod 2007;33:220-25. 
2

3

279 32.Alves FR, Siqueira JF Jr, Carmo FL, et al. Bacterial community profiling of cryogenically

280 ground samples from the apical and coronal root segments of teeth with apical periodontitis. J

281 Endod 2009;35:486-92.

282 33.Rocas IN, Alves FR, Santos AL, et al. Apical root canal microbiota as determined by reverse283 capture checkerboard analysis of cryogenically ground root samples fromteeth with apical 284 periodontitis. J Endod 2010;36:1617-21.

285 34.Miller TA, Baumgartner JC. Comparison of the antimicrobial efficacy of irrigation using the 286 EndoVac to endodontic needle delivery. J Endod 2010;36:509-11.

287 35. Wang Z, Shen Y, Ma J, et al. The effect of detergents on the antibacterial activity of 288 disinfecting solutions in dentin. J Endod 2012;38:948-53.

289 36.Gu LS, Kim JR, Ling J, et al. Review of contemporary irrigant agitation techniques and 290 devices. J Endod 2009;35:791-804. 
Figure1. (A) The antibacterial efficacy of $\mathrm{NaOCl}$ modified with BAK in teeth infected with $E$. faecalisdetermined from paper point sampling of the canal space. S1 valuesfor Negative Control and Positive Control Groupsarecompared to S2 (post-irrigation) valuesof $\mathrm{NaOCland} \mathrm{NaOCl/BAK}$ Groups. The reduction of canal bacteria for each tooth determined by paper point sampling was calculated as $100^{*}(\mathrm{~S} 1-\mathrm{S} 2) / \mathrm{S} 1$; where S1=Positive Control Group and S2=either $\mathrm{NaOCl}$ or NaOCl/BAK Groups. (B) Total bacteria/mg (Y-Axis) obtained from pulverization of tooth halves.

Figure 2. Representative CLSM images of BacLight ${ }^{\mathrm{TM}}$ stained tooth sections. (A) Tooth from $\mathrm{NaOCl}$ Group. The red fluorescence of propidium iodide is indicative of dead bacterial cells. The black area to the right represents the empty canal space, with very few living cells on the root canal wall. (B) Tooth from NaOCI/BAK Group. The canal is to the right. There has been a modest increase in clearance of bacteria adjacent to the canal wall (shown by the dark band of dentin without staining). The green fluorescence of SYTO9 represents live bacteria in the dentin tubules. (C) Representative CLSM image for Positive Control Group.A thick band of green fluorescent live cells (biofilm) is seen on the canal wall. 


\section{Paper point}

12

13

14

15

16

17

18

19

20

21

22

23

24

25

26

27

28

29

30

31

32

33

34

35

36

37

38

39

40

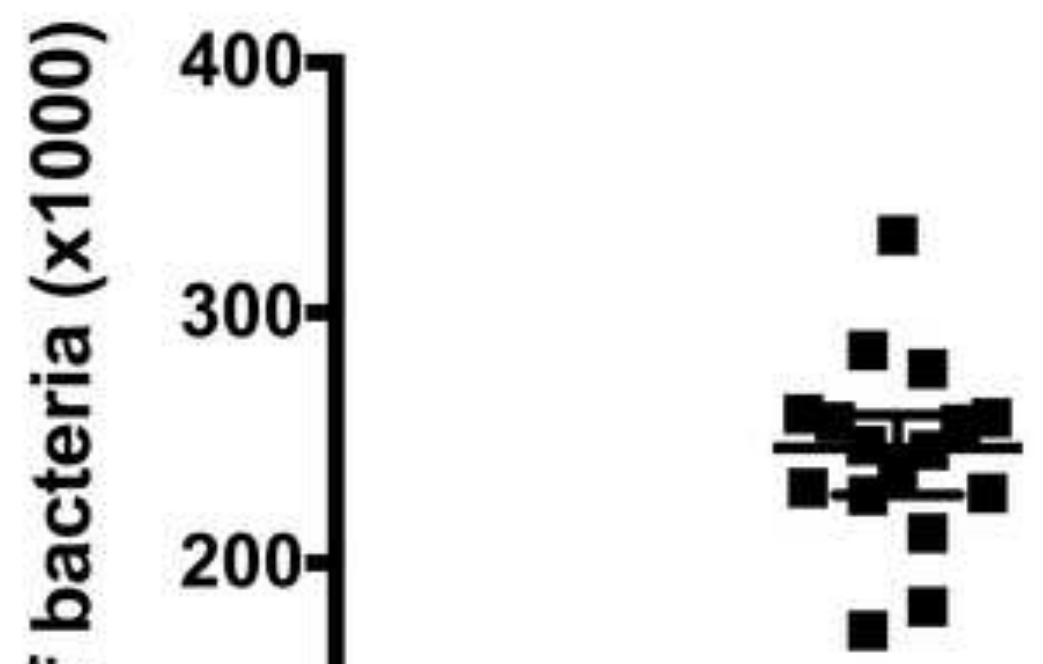

文

む) 100

$\Delta \wedge$

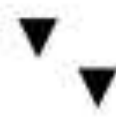

41

42

43

44

45

46

47

48

49

50

51

52

53

54

55

56

57

58

59

60

61

62

63

64

65

\section{Treatment Group}




\section{Tooth}

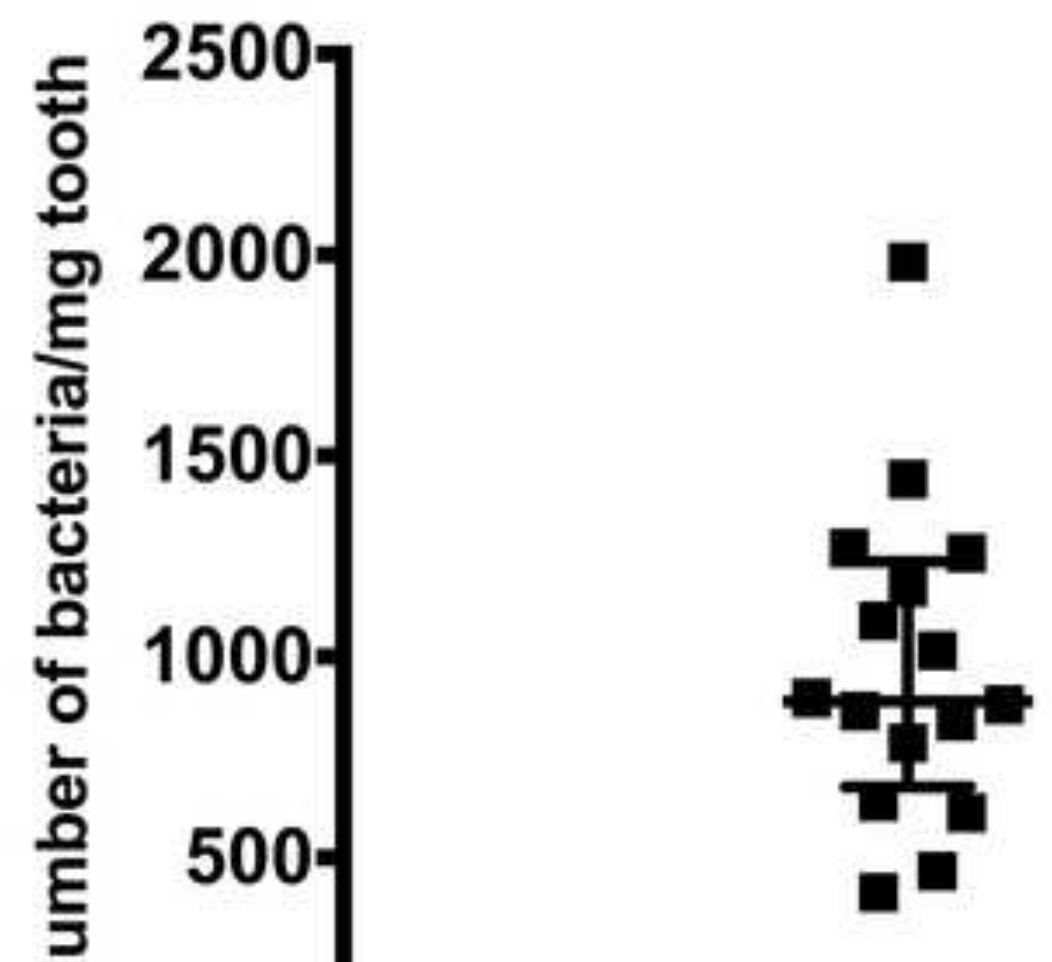

39 Z

40

41 
Figure 2A

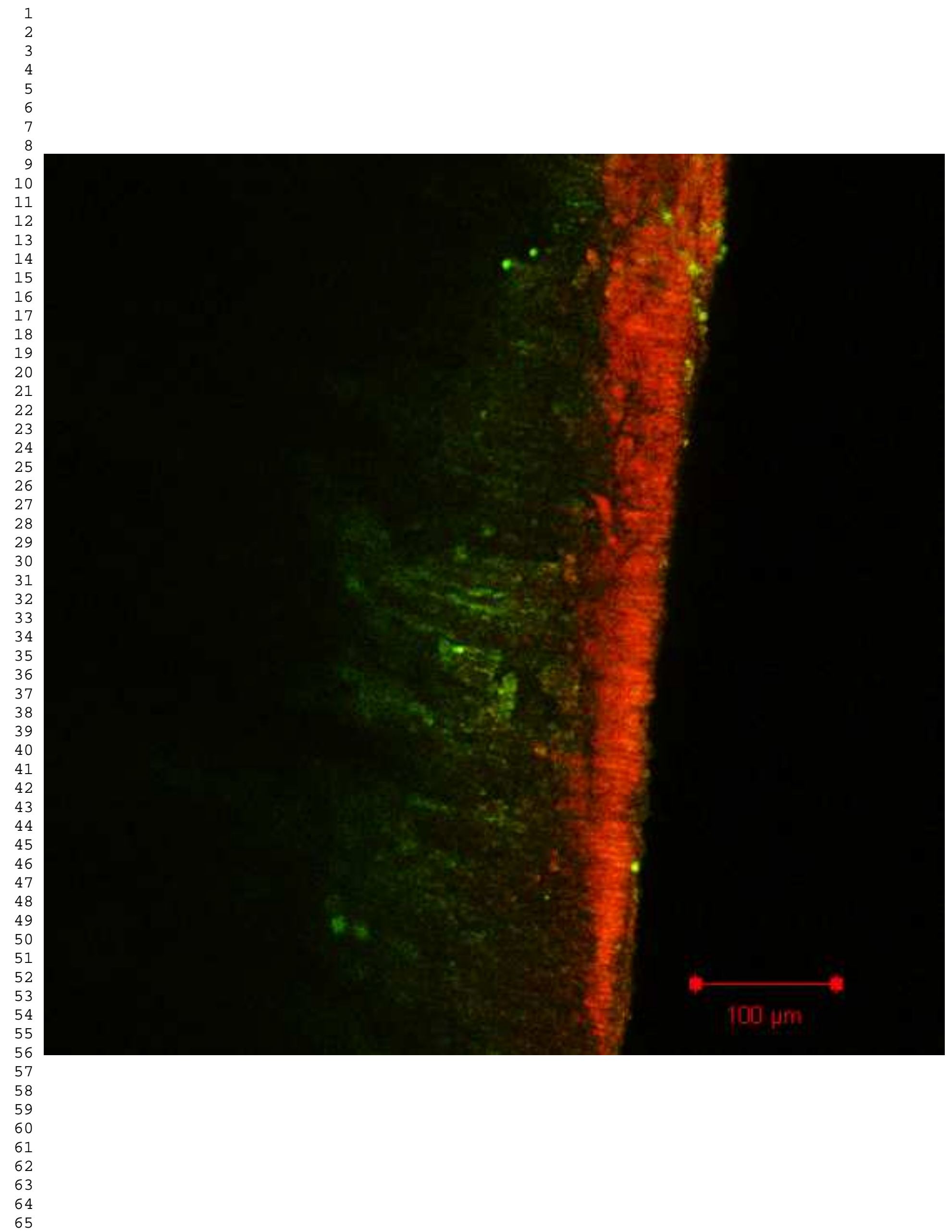




\section{Figure 2B}

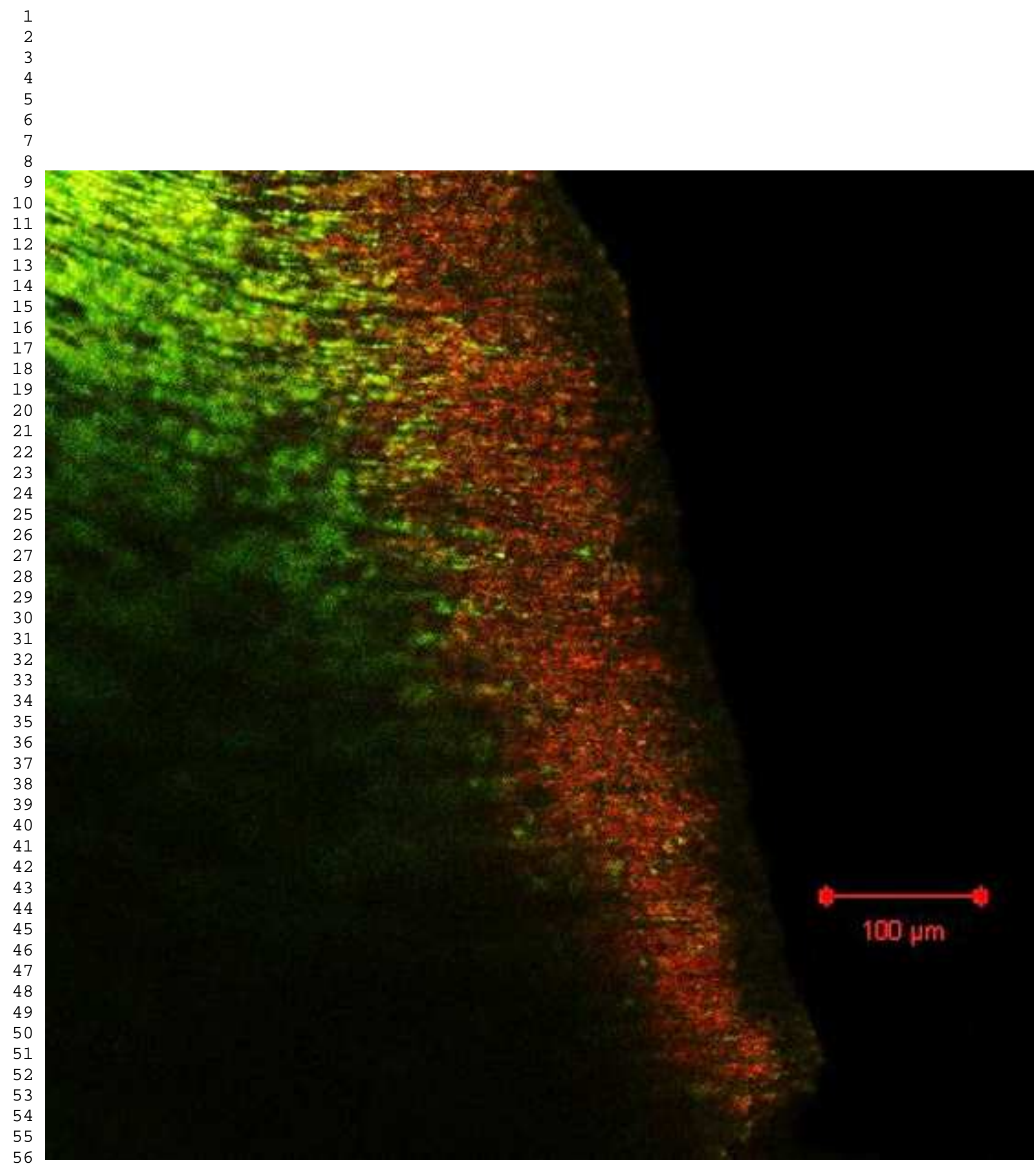

57

58

59

60

61

62

63

64

65

7

9

1

4

.

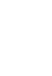

3

5


Figure 2C

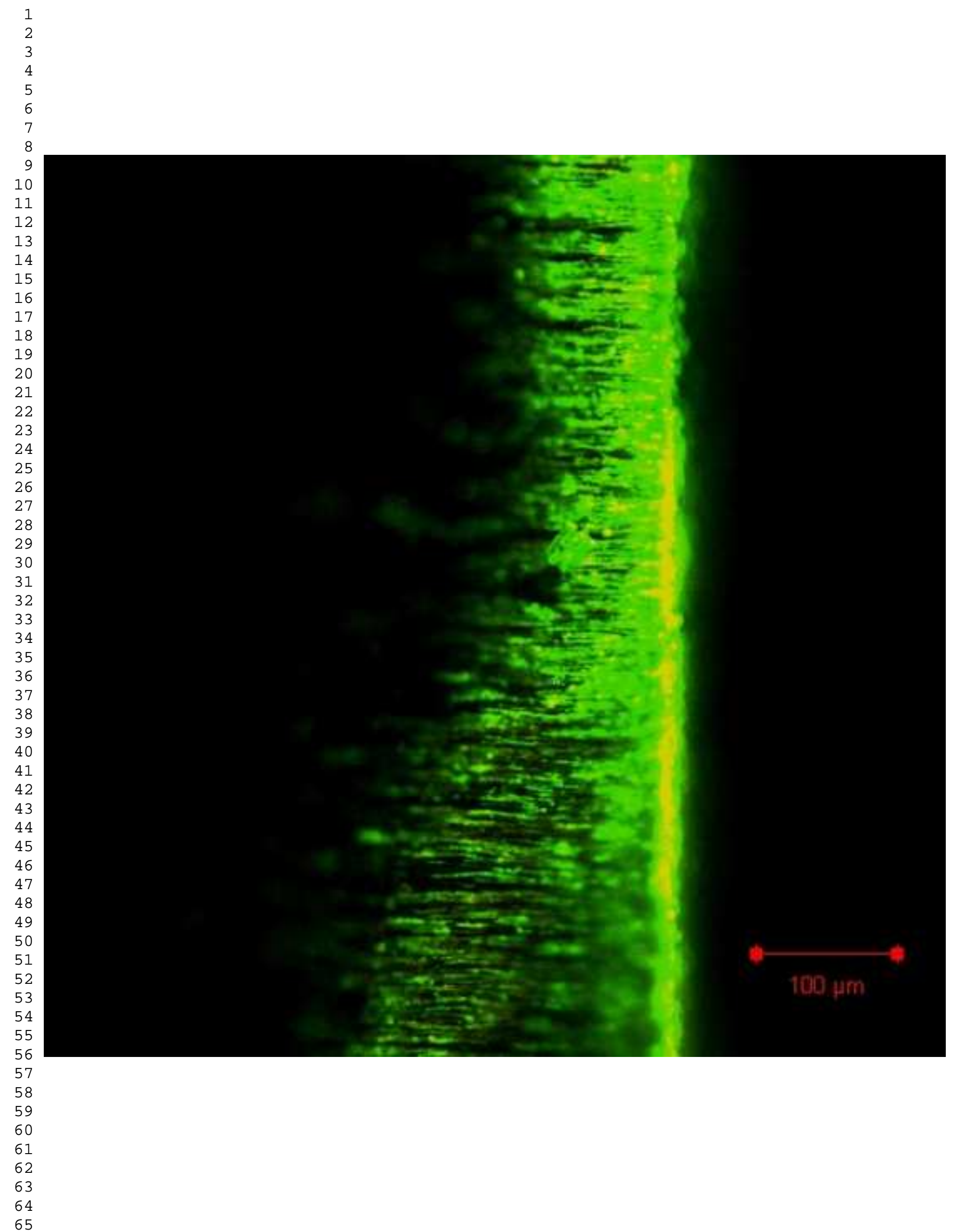

